\title{
"Cada comprimido é uma reivindicação de posse": ativismo e identidade no documentário Meu corpo é político
}

\author{
João Gabriel Maracci, Sofia Favero \& Paula Sandrine Machado*
}

Resumo: O artigo analisa como o documentário Meu corpo é político performa um modo específico de ativismo e de ação política. Investiga-se o enquadramento do filme a respeito da política, do corpo e da separação entre os planos público e privado, considerando que a abordagem contrapõe o enquadre usual da transexualidade, mas que opera sobre essa categoria a partir de um critério de veridicção pautado pelo ativismo. Palavras-chave: corpo; política; ativismo; transexualidade; documentário.

Resumen: Este artículo analiza cómo el documental Meu corpo é político lleva a cabo un modo específico de activismo y de acción política. Se investiga el marco de la película en lo que respecta a la política, al cuerpo y a la separación entre los ámbitos público y privado, considerando que el abordaje contrapone el enfoque usual de la transexualidad, pero actúa sobre esta categoría con un criterio de "veridicción" pautado por el activismo.

Palabras clave: cuerpo; política; activismo; transexualidad; documental.

Abstract: This article analyzes how the documentary Meu corpo é politico performs a particular way of activism and political action. We investigate the film's framework over politics, the body and the separation of public and private dimensions, considering that the approach contraposes the usual frame of transsexuality, but acts over this category using a "veridiction" criterion driven by activism.

Keywords: body; politics; activism; transsexuality; documentary.

Résumé : L'article analyse comment le documentaire Meu corpo é político promeut une manière spécifique d'activisme et d'action politique. On enquête sur le contexte du film en ce qui concerne la politique, le corps et la séparation entre les sphères publique et privée, en considérant que cette approche s'oppose à l'approche traditionnelle de la transsexualité, mais qu'elle opère avec un critère ou contrat de véridiction conditionné par l'activisme.

Mots-clés : corps ; politique ; activisme ; transsexualité ; documentaire.

* João Gabriel Maracci: Universidade Federal do Rio Grande do Sul, Instituto de Psicologia, Programa de Pós-Gradução em Psicologia Social e Institucional, 90035-003, Porto Alegre, Brasil. E-mail: jmaraccicardoso@gmail.com

Sofia Favero: Universidade Federal do Rio Grande do Sul, Instituto de Psicologia, Programa de Pós-Gradução em Psicologia Social e Institucional, 90035-003, Porto Alegre, Brasil. E-mail: sofia.favero@ hotmail.com

Paula Sandrine Machado: Universidade Federal do Rio Grande do Sul, Instituto de Psicologia, Programa de Pós-Gradução em Psicologia Social e Institucional, 90035-003, Porto Alegre, Brasil. E-mail: machadops@gmail.com

Submissão do artigo: 26 de outubro de 2018. Notificação de aceitação: 22 de janeiro de 2019. 
Meu Corpo é Político é um documentário lançado em 2017 que marca um processo de disputas no campo audiovisual brasileiro, sobretudo no segmento que se abre a diálogos com movimentos sociais. De antemão, a afirmativa de uma politização do corpo dá indícios do comprometimento com uma narrativa ativista. Mas de qual ativismo estamos falando? O corpo político, de fato, não deve ser compreendido fora das relações no qual se estabelece, até mesmo em esferas virtuais e contemporâneas das mais diferentes militâncias. Todavia, é preciso ter em mente que há um tom pronunciado que direciona a película. $\mathrm{E}$ é desse lugar que a produção da diretora Alice Riff aparenta falar.

A escolha dos personagens, ou dos sujeitos retratados, também parece ser fruto de contribuições críticas mais atuais. Três mulheres trans (ou travestis, ou transexuais) acompanham um homem trans ${ }^{1}$ na elaboração do documentário como os principais agentes daquele processo. Por esse ângulo, seria prudente afirmar que o tema central é gênero, mas não sem destacar que os marcadores raciais e de classe se expressam com uma intensidade similar - e essa afirmação se dá em decorrência da própria proposta do documentário, que é a de informar sobre tais diferentes atravessamentos identitários e seus impactos nas vidas de Linn da Quebrada, Giu Nonato, Fernando Ribeiro e Paula Beatriz.

Essas quatro figuras são, com maior ou menor repercussão, conhecidas por suas atuações em movimentos de luta pelos direitos de travestis e pessoas trans. Linn da Quebrada por suas performances musicais; Giu Nonato por seus vlogs e textos; Fernando Ribeiro por ser um ativista trans a partir do recorte transmasculino; Paula Beatriz por seu trabalho enquanto pedagoga e diretora de uma escola em São Paulo. Esses são aspectos explorados de antemão no documentário, o que fortalece o argumento de que Meu Corpo é Político propõe falar a partir de uma posição ativista. Mas que posição seria essa? A partir dessa pergunta, elaboramos o questionamento que embasa o presente artigo: como o documentário performa um modo específico de ativismo, e em qual concepção de política este se embasa?

A interrogação nos surge como um ponto de partida pertinente, posto que este não é um dado que serve apenas para saber a origem do roteiro ou a implicação dos personagens/sujeitos, mas para entender que uma série de códigos são disparados para delimitar os modos permitidos para se fazer política com aquele corpo. Entendemos o ativismo a partir da crítica de Abers e Bulow (2011), que o descrevem não apenas como uma forma de ação coletiva e transformadora voltada para o agrupamento de pessoas com identidades em

1. A escolha do termo "homem trans" acompanha as provocações de Oliveira (2014), quando o autor afirma que o uso da palavra "transhomem" seria inadequado para classificar essa população, pois daria a impressão de que ser trans é o aspecto central na vida do sujeito, e não uma característica dentre outras. 
comum, mas também como uma prática que atravessa outros modos de ação e organização social. Dentre essas outras formas, pode-se citar o campo digital como um atual espaço de luta e combate a desigualdades.

A proposta de que as redes virtuais configuram em novos espaços de construção política tem sido defendida por outros autores, como Machado (2007). Em sua perspectiva, as formas de organização dos movimentos sociais adquirem uma nova expressão quando confrontadas com o campo digital, desenvolvendo dinâmicas diferenciadas de ação que se coligam a redes identitárias orientadas por valores universais (Machado, 2007). Tais valores seriam referentes a minorias, direitos humanos e liberdade de expressão, o que na estética do presente trabalho se traduziria em marcadores sexuais, raciais e de gênero. Sendo que esses marcadores ocupam uma certa centralidade quando se pensa em ativismo virtual no contemporâneo, fazendo com que não raramente se relacionem com essa esfera digital da militância ${ }^{2}$ e até mesmo se confundam.

Por esse olhar, Meu Corpo é Político traz indicativos de operar por meio de códigos e princípios próprios de um ativismo que pertence ao contexto virtual, apesar de não se esgotar nele. Não se esgotar no sentido de que tais regulamentos escapam para as dinâmicas cotidianas, fazendo com que se produzam consequências no plano social. Esta reflexão, inclusive, toma palco no decorrer do filme, em uma cena na qual duas personagens conversam sobre uma polêmica relacionada ao ativismo que se tornou "viral" em redes sociais, tais quais o Facebook, no ano de 2017: o caso de uma adolescente branca que teria sido ofendida por militantes do movimento negro devido ao uso de um turbante.

$\mathrm{O}$ roteiro, materializado na conversa entre as personagens, emerge uma crítica a essa conduta, situando o lugar da militância virtual na composição do documentário como um eixo condutor das discussões que se apresentam, seja em forma de conscientização ou em forma de questionamento. Desta forma, esboça-se um entendimento acerca do enquadre utilizado pelo filme para performar noções específicas de política e de ativismo.

\section{Enquadramentos}

Nesta direção, questionamos o modo como o documentário enquadra as histórias de vida por ele apresentadas e sua ação no âmbito da política. O enquadramento - ou seja, o modo como a câmera coloca em cena determinados elementos, produzindo assim uma realidade sobre eles - é tomado como analogia para as dinâmicas de reconhecimento que operam no campo social. Para

2. Dizemos que raça, sexo e gênero se relacionam com a esfera digital da militância com maior expressividade pensando que coletivos e organizações voltadas ao debate da classe aparentam priorizar meios de mobilização mais tradicionais, como sindicatos. Embora, é claro, não signifique dizer que não existam páginas, blogs e sites voltados a essas discussões. 
Judith Butler (2015), a própria condição da vida é delimitada a partir do enquadre no qual esta é efetivada, referido às relações de poder que performam condições de possibilidade para a emergência de algo no mundo.

$\mathrm{O}$ reconhecimento, deste modo, diz respeito às relações de poder que demarcam enquadres específicos, fomentando delimitações possíveis para o entendimento da realidade. Essas delimitações, para a autora, conjugam esquemas de inteligibilidade, que condicionam as normas pelas quais a vida é reconhecida. Neste sentido, é no âmbito do poder que se conforma a inteligibilidade das relações sociais, repercutindo, por exemplo, nas categorias utilizadas para descrever - e consequentemente produzir - uma vida possível: identidade de gênero, orientação sexual, raça, entre tantas outras.

Sob essa perspectiva, pode-se afirmar que "as categorias dizem mais sobre a necessidade de categorizar os corpos do que sobre os próprios corpos" (Butler, 2011, p. 47, tradução livre), à medida que são essas categorias que permitem nossa existência social, podendo também ser mobilizadas através de ações políticas. Tais ações deslocam os pressupostos da inteligibilidade, de modo a apontar para uma compreensão não fixa ou essencialista do reconhecimento. As categorias, pelo contrário, se por um lado são reiteradas citacionalmente em nossas práticas cotidianas, por outro também apresentam falhas e fissuras inerentes, que permitem sua constante reconfiguração no tecido social.

Desta forma, há sempre algo que escapa do controle da inteligibilidade, ou seja, algo que não se restringe "ao contexto que enquadra o acontecimento" (Butler, 2015, p. 25). Seja a partir do que uma câmera não enquadra, mas revela, ou pela analogia que tal procedimento performa em uma compreensão social, pode-se afirmar que o enquadre não totaliza a verdade sobre o que é enquadrado, de modo que sempre possa haver um excesso, ou algo que transborda em novas interpretações, compreensões, paródias, dúvidas.

Este é o caso do documentário Meu Corpo é Político, que fornece um enquadre para as experiências das quatro pessoas retratadas pautado por sua ação política e pela potência de seus corpos na assunção de uma identidade contraposta à cisgeneridade ${ }^{3}$ e heterossexualidade compulsórias. Para tanto, a busca pela política do corpo se dá menos no espaço público, plano tradicional da experiência política, do que no âmbito privado, enfocando as relações familiares, domésticas e de amizade dos protagonistas - assunto que será abordado nos tópicos a seguir.

O enquadre da vida privada não apenas delimita politicamente o conteúdo do documentário, mas é também performado pela sua própria linguagem visual e narrativa. A câmera, que acompanha os participantes nos seus locais de

3. Cisgeneridade, de acordo com Jesus (2015), é a condição daquele que não é trans. 
trabalho, trânsitos pela urbe, no transporte público, nos seus carros e casas, aparentemente não é vista ou percebida. Giu Nonato, por exemplo, é filmada em uma parada de ônibus fumando um cigarro e, em determinado momento, olha para a câmera sem a "ver" - como se não fosse a cena de um filme, mas sim uma cena trivial de sua própria vida.

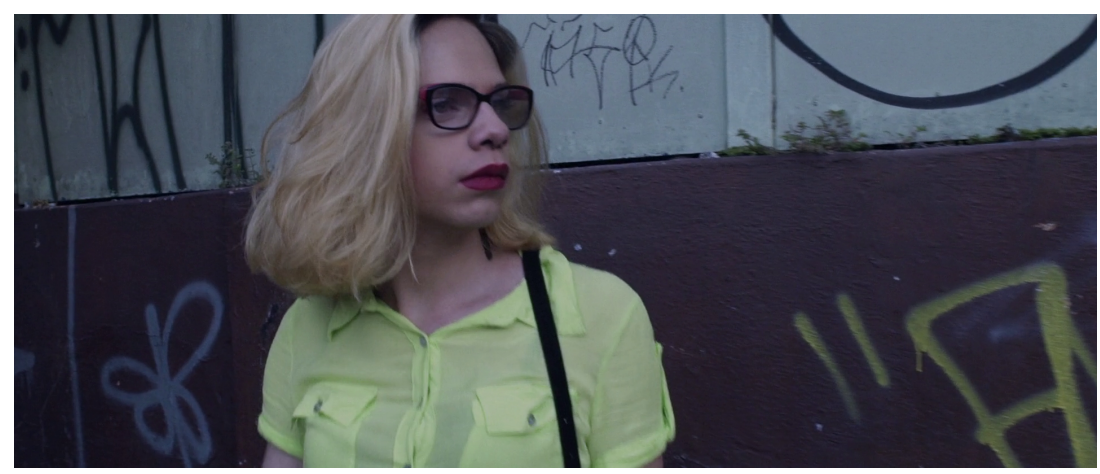

Figura 1. Giu olha para um ponto indefinido como aspecto de reflexão.

As definições de realidade ou ficção que podem ser extraídas de um documentário apresentam vasta discussão, seja na literatura ou no entendimento prático a respeito dessa modalidade cinematográfica (Rodrigues, 2018; Salles, 2005). Não é nossa intenção adentrar tais controvérsias, mas apenas apontar que a estratégia narrativa de "desaparecimento" da câmera no documentário específico parece performar um enquadre de "realidade" na história que é contada, colocando o espectador em uma posição de "voyeur" frente àquelas vidas - apresentadas em sua "naturalidade", como se não fizessem parte de um filme.

Deste modo, o enquadre performa um reconhecimento das vidas que pretende exceder a película: nos deparamos não simplesmente com um documentário sobre quatro pessoas trans, mas sim com as suas próprias vidas, acompanhadas por uma câmera invisível. No entanto, se, como vimos, os sentidos para um acontecimento por vezes transbordam o modo como é enquadrado, o que pode escapar desta narrativa em Meu Corpo é Político?

Primeiramente, pode-se afirmar que o enquadre do documentário performa um acesso à vida das personagens tal qual ela é para além dos limites do filme. Deste modo, supomos que aquelas vidas são, de fato, pautadas pelo ativismo e que aqueles corpos se efetivam politicamente no cotidiano, com ou sem as câmeras que os recortam. Assim, se assumimos que o ativismo procede de maneira central na vida dos quatro protagonistas, os esforços para situá-los em outros campos (como em casa, na rua e no trabalho) estariam atravessados por 
uma militância constante. Algo que, embora faça sentido para algumas pessoas trans, esbarrara na ideia de que cabe a elas o papel de questionar incessantemente as normas de gênero. Meu corpo é político começa, aqui, a desenhar uma fisionomia para o que entende como politização do corpo, que seria, dentro de uma das leituras possíveis, relacionado à capacidade de questionar.

Essa assunção de uma verdade exterior à narrativa parece retomar o que Foucault (1999) nomeou como "regime de veridicção", ou seja, o arranjo biopolítico que garante o estatuto de verdade para algo no mundo a partir das relações de saber e poder nas quais se insere. Em relação às experiências de transexualidade e travestilidade, este regime de veridição é constantemente reiterado à medida que, no Brasil, é protocolar a necessidade de um laudo psicológico para a realização do tratamento hormonal e cirúrgico destinado a essa população, conforme regulamenta o Sistema Único de Saúde (SUS). Os critérios para este laudo são de via patologizante, referenciados pelo DSM- $5^{4}$, sob o nome de Disforia de Gênero (American Psychiatric Organization, 2013) e pela CID- $10^{5}$, nomeado ainda como Transtorno de Identidade de Gênero ${ }^{6}$ (Organização Mundial da Saúde, 1997). Por esses veículos é que se torna comum uma referência às identidades trans e travestis como clinicamente avaliáveis.

Em função desta exigência, é necessário que as pessoas trans comprovem, no ambiente clínico, a verdade de sua experiência para além deste contexto, de modo que sejam recorrentes narrativas que expõem estratégias de "exagero" ou até mesmo "fingimento" frente aos profissionais da psiquiatria ou psicologia, para que estes legitimem a masculinidade ou feminilidade do paciente conforme o esperado pelos critérios nosológicos. Neste sentido, para ser tratado como verdadeiramente trans nos serviços de saúde, é preciso primeiro ser reconhecido como tal e, para tanto, exige-se uma conformidade à delimitação psicopatológica, baseada em ideais e estereótipos do binário de gênero (Bento, 2006).

4. "Manual Diagnóstico e Estatístico de Transtornos Mentais".

5. "Código Internacional de Doenças".

6. Atualmente, a revisão da CID 11 tem proposto alterar o Transtorno de Identidade de Gênero para a nova classificação de "Incongruência de Gênero". Embora essa mudança apareça como um pressuposto despatologizante, ainda investe em uma prática diagnóstica para garantia de direitos. 


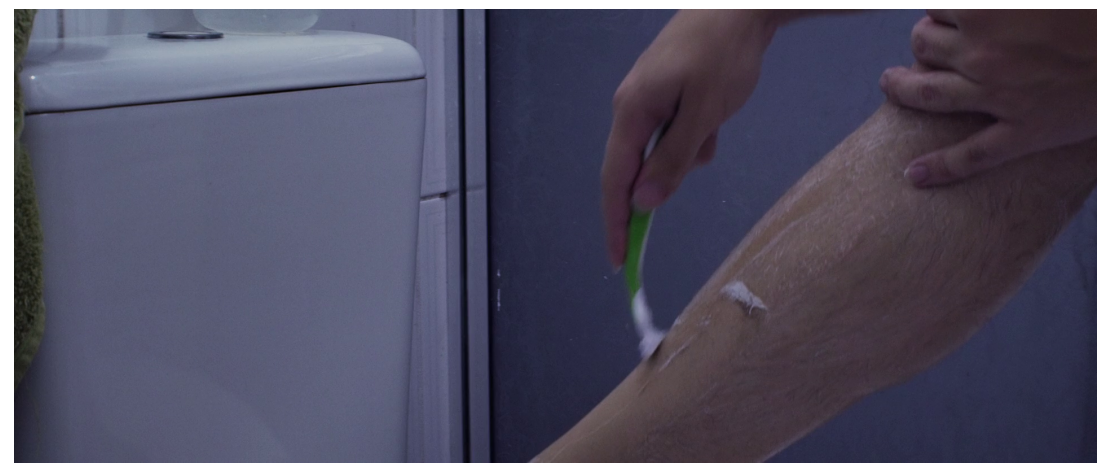

Figura 2. Giu depila as pernas, colocando em questão o campo das masculinidades e feminilidades.

Meu Corpo é Político contesta o enquadre psicopatológico da experiência trans, exibindo a vida de pessoas em situações que não seriam contempladas pelas atribuições diagnósticas da CID-10 ou do DSM-V. No documentário, falase abertamente sobre masturbação, sobre a utilização do corpo como forma de prazer para si e para outrem, sobre um corpo desejável e desejante. Em determinada cena, uma das personagens usa um barbeador para depilar suas pernas e seu rosto, em movimentos seguros que não demonstram qualquer restrição ou vergonha daquele ato. Dado que a "ojeriza ao próprio corpo" figura como critério de exclusão para o diagnóstico nos dois manuais citados, percebe-se que a película opera em um sentido oposto, contestando a nosografia psicológica e psiquiátrica na afirmação de um orgulho, e não vergonha, sobre o próprio corpo.

No entanto, o enquadre do ativismo, que se presentifica desde o título do documentário, parece performar ainda outra forma de veridicção - seguramente não mais relacionada aos critérios e expectativas dos manuais diagnósticos, mas que se ancora nas referências políticas que envolvem o corpo retratado e produzido na narrativa. A "câmera invisível", que acompanha a vida das personagens como se não estivesse lá, afirma desta forma a verdade sobre essas vidas e corpos: são, indiscutivelmente, políticos. É nesse cenário que determinado "gênero ativista" (questionador, crítico e desconstruído) concorre com o "gênero nosológico" (diagnosticável, estereotipado e tutelado), disputando a inteligibilidade trans na película, de modo a apontar para a concepção de política que embasa a circunscrição desses corpos através do documentário. 


\section{Política}

A assunção do caráter político do corpo não é consenso nos debates sobre teoria ou filosofia política, de modo que esta hoje emerja como uma das controvérsias centrais para o desenvolvimento de tais áreas do saber. Meu corpo é político assume uma posição nesta disputa, afirmando a capacidade do corpo enquanto agente político desde seu título até às narrativas das pessoas retratadas.

Em uma cena de diálogo entre Giu Nonato e sua amiga, uma mulher cis negra, ambas discutem a criação de um grupo no Facebook para a troca de autorretratos com nudez destinado a pessoas cujos corpos usualmente não são contemplados pelos critérios estéticos tradicionais. Em seguida, realizam um ensaio fotográfico, no qual Giu retrata, com seu celular, o corpo gordo e negro da outra mulher em cena. Ela afirma:

Eu comecei a fazer as fotos porque eu criei um grupo no Facebook, é um grupo que pretende ser um espaço o mais seguro possível para pessoas que têm problema com o corpo, com a autoestima, que por algum motivo o seu corpo gera algum preconceito ou uma marginalização na sociedade. Para as pessoas poderem publicar fotos desse corpo lá, as famosas nudes. (...) Não é necessariamente um espaço erótico, mas é um espaço onde as pessoas podem manifestar o desejo, até para as pessoas se sentirem desejadas..

Ao que a amiga responde afirmativamente: "É um espaço de empoderamento". Tal conversa parece indicar a concepção de política na qual se embasa o documentário, tendo nos despertado o seguinte questionamento, para o qual talvez o filme seja justamente uma resposta: o que pode um corpo no plano da política? Deste modo, buscamos, a partir da película, conjugar sua proposta aos debates contemporâneos acerca do corpo e sua agência, compreendendo-a não apenas como um retrato de uma ação corporificada, mas sim como parte de um agenciamento que opera na produção de condições de possibilidade para a emergência de determinados ativismos.

Ao pensar sobre o lugar do corpo na política, retomamos Hannah Arendt (2014), para quem a condição humana divide-se em três aspectos: Trabalho, Obra e Ação ${ }^{7}$. As duas primeiras - que, respectivamente, dizem respeito às necessidades biológicas da vida em um cunho natural e à capacidade humana de criar objetos que permanecem para além de sua existência no mundo - são tomadas pela autora como anteriores e condicionais à emergência da política. Essa, referida apenas ao plano da Ação, não seria natural do humano, mas sim

7. Utilizamos a $12^{\mathrm{a}}$ edição do livro A Condição Humana traduzida para o Português, em que a palavra inglesa "Labor" corresponde a "Trabalho" e "Work" a "Ação". Nas versões anteriores, os termos utilizados são "Labor" e "Trabalho", respectivamente. 
contingente a determinadas situações nas quais se torna possível sua aparição, como foi o caso da polis grega.

Para Arendt, a política na ágora estava condicionada pela divisão rígida entre os planos público e privado, de modo que o segundo servisse como base para a eclosão do primeiro. Deste modo, Trabalho e Obra diriam respeito à esfera privada da vida, em um aspecto pré-político, no qual estariam situados o corpo e as atividades laborais e domésticas. A ação, por outro lado, só seria possível dadas condições muito específicas, nas quais o sujeito - que necessariamente era homem e não escravo - podia ocupar o espaço da cidade e, em conjunto com outros homens, finalmente agir - sendo esta a configuração fundamental da política.

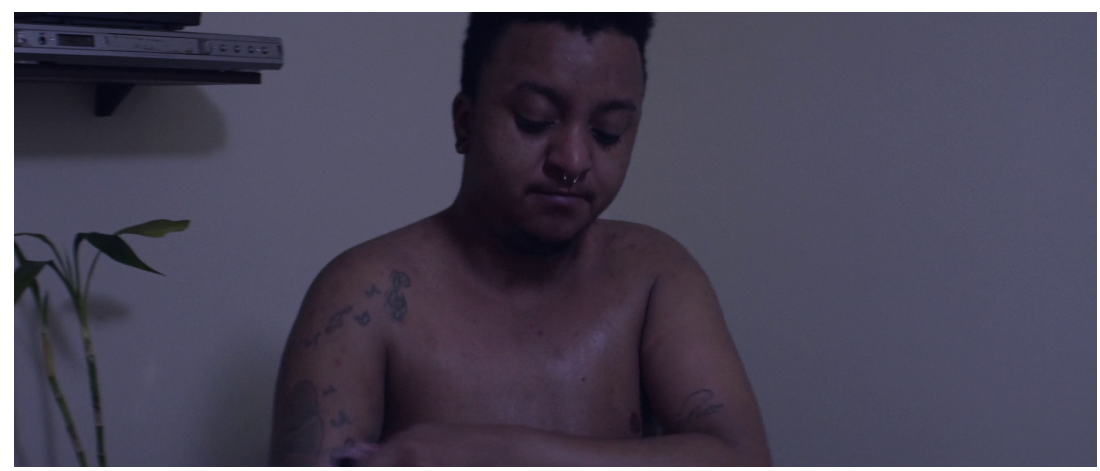

Figura 3. Fernando expõe os resultados da mamoplastia masculinizadora - ou mastectomia, como costuma ser chamada por alguns campos da medicina.

Neste sentido, a assunção política jamais poderia ser atribuída ao corpo, à medida que esta se basearia em uma ação conjunta no espaço público que transcendesse e superasse o plano privado. As demandas corporais, bem como as relações domésticas e do mundo do trabalho, seriam da ordem da necessidade, estando por isso apartadas da política, visto que esta seria somente acessível mediante à sua superação. Deveríamos, desta forma, considerar $\mathrm{Meu}$ corpo é político como uma contradição em termos, no intento de politizar aquilo que performa o exato oposto da política?

Em diálogo com a teoria arendtiana, Judith Butler (2018) propõe uma versão corporificada da política. Para a autora, os processos corporais, como o nascimento e a morte - relacionados por Arendt à esfera do Trabalho - não estariam separados do plano público, à medida que as condições de produção e manutenção de um corpo no mundo partam também de um aspecto político. Butler afirma que a precariedade - ou seja, a constante possibilidade de ex- 
posição à morte - funciona como uma ontologia social da vida, de modo que esta seja possível apenas mediante a uma rede de conexões entre humanos e não humanos, que garante certa estabilidade para a existência. Rede esta que é facilmente desfeita em situações como guerras, atentados, momentos de violência, o que converge na concepção de que a precariedade, embora comum a todos, é distribuída de forma desigual, a partir de critérios inevitavelmente políticos.

Neste sentido, o corpo não seria um espaço anterior ao plano público, a ser "superado" na via de uma ação - pelo contrário, o corpo é o espaço efetivo da política, de modo que suas "necessidades" não se deem em um espaço prédiscursivo ou anterior à ação, como pretendia Arendt, mas sim mediante a uma rede desigual de partilha da vulnerabilidade. A precariedade, assim, não é tomada como um elemento privado da condição humana, mas como a condição de possibilidade para a emergência da ação, de modo que a agência política parta do próprio corpo, e não de sua transcendência. Para Butler:

(...) já estamos no político quando pensamos sobre transitoriedade e mortalidade. Isso não significa que em um mundo justo não existiria mortalidade! (...) Significa apenas que um compromisso com a igualdade e a justiça implicaria abordar em cada nível institucional a exposição diferencial à morte $\mathrm{e}$ ao morrer que atualmente caracteriza a vida dos povos subjugados e dos precários, muitas vezes como resultado do racismo sistemático e das formas de abandono calculado (2018, p.55).

Deste modo, um dos aspectos fundamentais para entender o que o documentário quer dizer por politização do corpo é a partir da autonomia, ou, mais precisamente, através de uma certa capacidade do sujeito posicionar a si mesmo no mundo. Para Mbembe (2018), a política é o funcionamento da razão no campo público. E essa é uma proposta amplamente abordada na película, quando os personagens passam a se colocar através de suas próprias lentes. Desde Giu criando um grupo de nudes no Facebook a Fernando decidindo por qual nome quer ser chamado, há uma impressão de autonomia pautando essas relações. Autonomia, no sentido clássico, como algo que se fundamenta na "crença de que o sujeito é o principal autor controlador do seu próprio significado" (Mbembe, 2018, p. 10).

Se essa concepção de autonomia é, por nós, acolhida prematuramente, corre-se o risco de pormenorizar os próprios endereçamentos que aparecem no decorrer do documentário. $\mathrm{E}$, assim sendo, nenhuma daquelas quatro pessoas seria interpelada (na rua, na casa ou no trabalho) pela violência de tais endereçamentos. Viado, travesti, sapatão e outras formas de localizar o Outro no mundo, por meio de um suposto lugar inferior. Todavia, aqui compreendemos o que aparece como "autonomia" através da concepção foucaultiana de 
resistência. Resistência, para Foucault (1997), diz respeito às disputas com a liberdade, em uma função complementar, no sentido de que liberdade e resistência se provocam enquanto contiguidades.

Sendo assim, não existiriam relações de poder sem a possibilidade de resistência (Foucault, 1997), e é essa capacidade de resistir em um cenário de desigualdades que nos interessa pensar. Como Paula articula sua identidade com a profissão que exerce? Quais possibilidades Linn tem de se expressar no cenário musical mainstream/underground? De que forma a insubmissão de Giu, ao aparecer depilando o rosto e as pernas, tensiona e amplia os limites das normas de gênero? De outro modo, a trama da autonomia aqui exibida seria, aparentemente, bem menos complexa, simplista, relativa apenas ao modo que os sujeitos querem agir dentro de uma jornada pelo autoconhecimento.

É por esse ângulo que Meu Corpo é Político expressa sua ruptura com um modo tradicional de clínica, voltado prioritariamente à percepção de si, mas não sem romper juntamente a essa necessidade de fixar o gênero em algum terreno. Se antes, em atendimentos de saúde mental direcionados a travestis e pessoas trans, iniciava-se uma busca pela autenticidade - movimento que Prado (2018) nomeia como patologização do olhar, da escuta, do pensar e do perguntar -, no documentário, o que aparece é uma certa politização da própria matéria. Não significa dizer que o corpo não era político, mas que os modos de olhar, escutar, pensar e perguntar passam a ser também modos de questionar. O que é ser mulher? O que é ser homem? Masculino e feminino servem a todos? A partir do enunciado "meu corpo é político" não é feita apenas uma escolha pela exposição da vida na esfera pública, é aí que também se fixa o gênero em um terreno de interrogações.

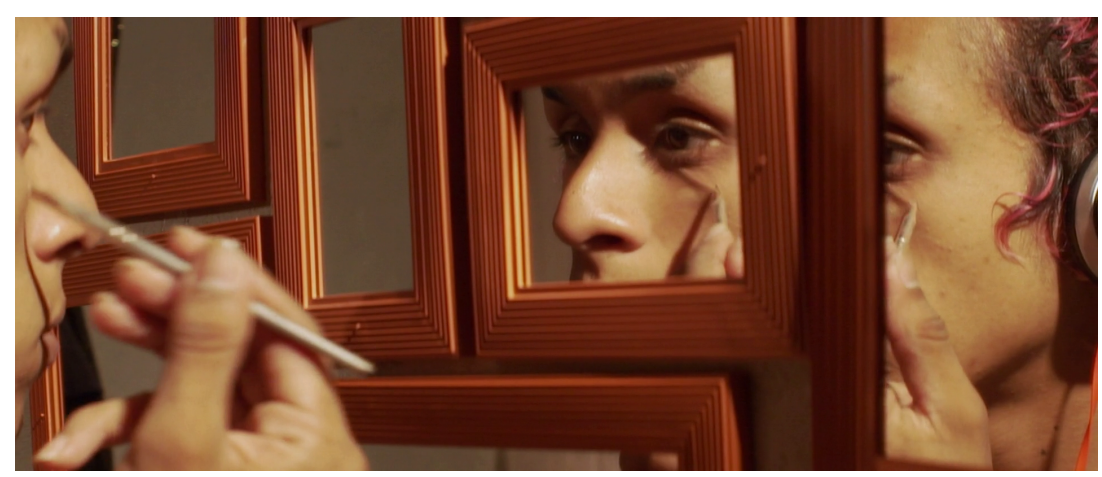

Figura 4. Linn se maquia frente a uma série de espelhos. 


\section{Público e Privado}

A captura de Linn observando diversos espelhos enquanto se maquia cumpre uma dupla função no presente trabalho. Se, por um lado, faz alusão às diferentes produções sobre travestilidade que disputavam a cena, por outro também (re)assegura a posição do documentário a respeito do enquadre de veridicção por ele performado. Linn, em um primeiro momento, parece se dirigir, pela primeira vez, diretamente ao espectador, com uma conversa acerca de sua história de vida e juventude, quando era Testemunha de Jeová. No entanto, ao que a câmera se afasta, compreendemos que se trata, na verdade, de um diálogo com Jup do Bairro, militante LGBTQI+ e presença constante nos videoclipes da cantora. Nos reflexos dos espelhos, pode-se notar que a cena é filmada desde um local escuro, onde a câmera segue escondida.

Pelo enquadre de invisibilidade da câmera, são aspectos específicos da vida das personagens os que tomam palco no documentário: a vida no lar, o cotidiano de trabalho, as relações afetivas. Dessa forma, público e privado passam a se constituir como uma ambivalência congênita para o filme. E aqui Meu Corpo é Político ganha outra camada, que diz respeito à luta diária de ser quem se é. Ter um corpo político é, necessariamente, optar (ou ao menos aceitar) a exposição deste corpo. Mas quais rotinas estão aptas à reflexão da coletividade? Esse processo, por mais que vise a uma politização das identidades, não dificultaria a compreensão de que "existem outras formas de lidar com a exclusão e com os processos de abjeção que se distanciam dos modelos de resistência heroica" (Lima, Machado e Pereira, 2017, s/p)?

Tal discussão não surge para classificar que, caso a câmera aparecesse e o documentário tomasse o formato de entrevista, as histórias soariam mais verdadeiras ou próximas a um ideal de realidade. Nosso enfoque não supõe um acesso à verdade exterior ao documentário, mas sim ao "efeito de verdade" por este promovido, na performação de uma realidade para a política dos corpos, sustentada na sua existência privada e doméstica - que contraria as formas tradicionais de entendimento da política, baseadas na circulação e ação no plano público. Neste sentido, talvez a única cena que se assemelha à compreensão política usual é a de Paula, em uma assembleia, afirmando verbalmente seus direitos e denunciando as violências que já enfrentou enquanto professora e mulher transexual. 


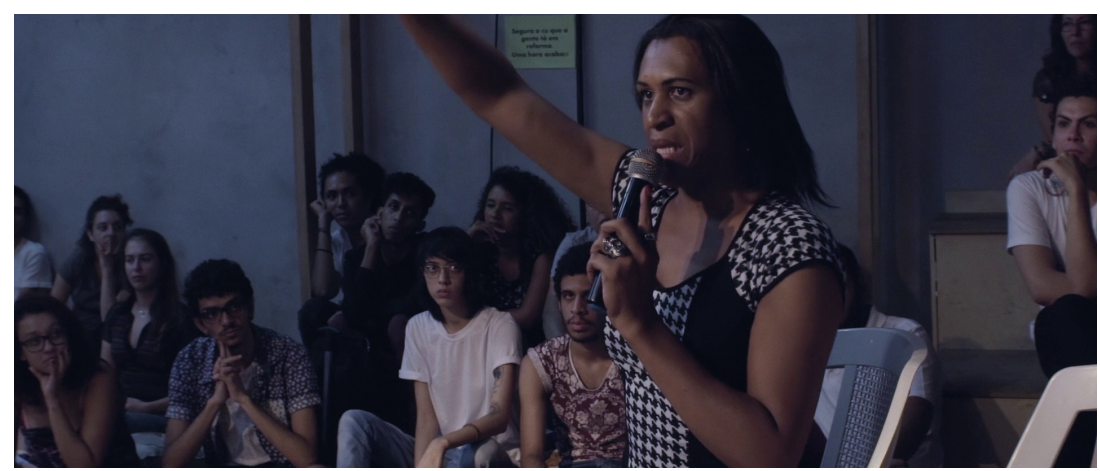

Figura 5. Paula faz uma fala/protesto em um evento, remetendo aos modos tradicionais de organização popular.

Nos outros momentos do documentário, a assunção de uma autonomia para o próprio corpo se dá majoritariamente no plano privado e doméstico. Por exemplo, na cena em que Giu Nonato lê sozinha, deitada em sua cama, uma poesia escrita em um diário, afirmando a resistência política travada na administração de seu corpo. Ela afirma:

Desde muito cedo meu corpo foi ocupado por intervenções cirúrgicas, hérnia inguinal, fimose endoscopia. Talvez hoje cada comprimido de hormônio seja uma reivindicação de posse sobre esse corpo. A cada comprimido eu me caibo melhor nessa pele. Esse adonar-se de mim mesma alivia qualquer preocupação com possíveis riscos: o fígado, os rins, o coração. Todo corpo pode falhar, mas ainda assim vai falhar dentro do meu campo de escolhas, limitado que seja..

Neste sentido, a politização do corpo se dá, primeiramente, em um contexto privado, não apenas da casa, mas da própria relação consigo mesma. Giu, que apresenta uma história de vida na qual não foram poucas as intervenções externas sobre seu corpo, assume a autonomia em relação a si quando passa a administrar as intervenções que ela mesma realiza, materializadas em sua transição de gênero. No entanto, se tal "reivindicação de posse" é assumida em um plano de intimidade - o quarto e o diário -, não se pode dizer que fica restrita ao privado e doméstico, à medida que é este mesmo corpo que anda pelas ruas, trabalha, e assume diversos outros contornos quando adentra o espaço público e coletivo.

Assim, entendemos que a compreensão política que embasa o documentário, embora refira-se majoritariamente à existência na esfera pessoal ou doméstica, só é possibilitada por uma zona de indiscernibilidade entre público e privado, na qual os corpos das personagens transitam com maior ou menor 
maleabilidade. O corpo político, aqui, performa um outro entendimento para a política, que assume sua condição precária e mobiliza, a partir dela, cuidados e intervenções sobre si dos quais os sujeitos não se afastam quando assumem posições no espaço público. Como afirma Butler em relação aos pressupostos arendtianos, a necessidade do corpo não pode ser tomada como anterior à política, à medida que tais necessidades são distribuídas - e também administradas - sob critérios políticos.

Deste modo, pode-se relacionar o entendimento do documentário acerca do ativismo e da política ao slogan clássico do movimento feminista: "o privado é político". No entanto, tal afirmativa é tomada não pelo adentramento do público em relação ao privado, expondo que as configurações privadas já são, em certa escala, delimitadas pelo público - mas sim na manutenção da zona de indiscernibilidade, na qual a autonomia frente ao corpo figura como agência de transitar entre os dois pólos. Por essa razão, supomos que a frase do título poderia ser complementada da seguinte forma: "Meu corpo é político, mas não é público" - pensando no público como algo de domínio comum, do qual não se pode tomar posse, visto que já é de todos.

Assim, a cena final do filme ilustra a ambivalência entre os planos e as pontes que os podem conectar. Nela, Paula fala o telefone com alguém que aparenta relacionar-se afetivamente. Na conversa, entende-se por suas respostas, já que não se pode ouvir o interlocutor, que se trata da combinação de um encontro, frustrado inicialmente por este estar "corrido no trabalho". No desenrolar da conversa, a câmera filma as luzes da cidade à noite, mostrando o bairro de classe popular onde Paula reside. Neste momento, a fala de Paula torna-se narração para a imagem pública, e a cena privada, referente a uma relação íntima, toma contornos mais amplos à medida que o enquadre deixa de ser a domesticidade, e sim o ambiente externo, viabilizando compreensões possíveis para os enlaces múltiplos entre a casa e a rua.

\section{Considerações Finais}

Meu Corpo é Político levanta uma série de discussões, muitas delas pensadas através da ótica de um ativismo originado de contextos digitais. E levantar os códigos que compõem esse contexto é fundamental para entender a motivação e implicação dos quatro sujeitos ilustrados ao longo do documentário. Palavras de ordem, protestos corporificados, reivindicação de afetos, essas e outras questões aparecem a partir de um vetor virtual que conduz os modos pelos quais os questionamentos (raciais, sexuais e de classe e de gênero) se apresentam. 
Nesse sentido, as redes sociais também aparentam desempenhar um papel igualmente expressivo na produção da película, uma vez que se tornam o campo em que é possível materializar algumas das disputas desempenhadas por Giu, Fernando, Paula e Linn. Essa indicação sugere que as formas tradicionais de fazer política, de lutar por direitos sociais, têm se (re)significado a campos cibernéticos, fazendo com que seja importante prestar atenção à ambivalência de um corpo que é político, mas de um corpo que também é digital. E o documentário brinca com tal ambivalência, assim como perturba também a antiga dicotomia entre público e privado, por meio de uma certa condição de precariedade que impossibilita a totalidade de tal distinção.

Mas o que é, afinal, um corpo político? Dentre os fatores listados ao longo do trabalho, pode-se citar três principais aspectos para configurá-lo. Um corpo político é aquele capaz de questionar os padrões de feminilidade e masculinidade, no sentido de desconstruir princípios binários acerca da anatomia de um homem e de uma mulher. Um corpo político é aquele que recusa o enquadramento clínico, mas que ao mesmo tempo escolhe para si determinado enquadramento de luta, fazendo com que a visibilização da própria carne se transforme em um ato de confronto. E, além disso, um corpo político é aquele que se utiliza da esfera público e privada para tensionar e possibilitar mais autonomia para a coletividade. O corpo, por esse ângulo, não deve ser lido precocemente como sinônimo de individualidade.

Essa perspectiva é apresentada quando Linn ministra uma dinâmica, na qual os participantes confundem coletivamente suas identidades, e as deslocam para provocar um compromisso ético com as perspectivas levantadas. Mulher. Negra. Trans. Bicha. E tantos outros marcadores que vão surgindo e sendo ditos em tom alto pela voz do grupo. Nesse momento se articula uma aliança refletida através da condição precária daquelas pessoas que se reuniram, tratando-se de uma cena que solidifica a proposta de que o corpo político, apesar de ser um termo no singular, está vinculado a outros corpos políticos, que também pensam modos de expansão das possibilidades de ação e resistência. 


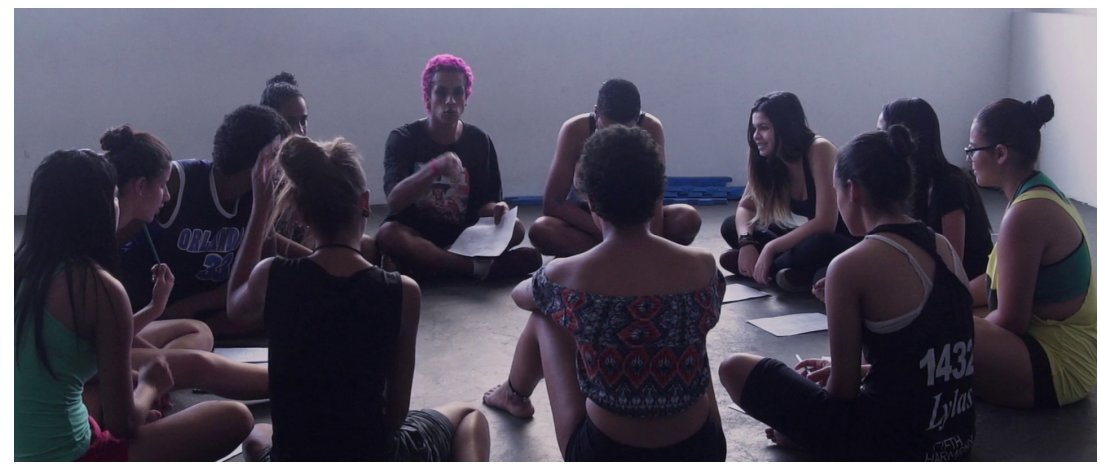

Figura 6. Linn e outras pessoas finalizam a atividade sobre gênero, sexualidade, raça e classe.

O desafio aparece quando essa resistência tem que se dar na experiência do corpo, porque embora seja esse o espaço no qual as subalternizações se materializam, a ideia de que as disputas por direitos e reconhecimentos sociais ocorram na constituição física pode ser prejudicial aos próprios agentes desse processo. Ora porque essas formas de instrumentalizar o corpo podem atribuir a essas pessoas a responsabilidade incessante de questionar as normas hegemônicas, ora porque essa exposição pode não ser desejada por todas as pessoas que compõem esse determinado contingente populacional. Dessa forma, convém considerar a potência de ter o próprio corpo como ferramenta de luta sem fazer com que, junto a isso, a possibilidade de viver seja perdida de vista.

\section{Referências}

Aberd, R. \& Bulow, M. (2011). Movimentos sociais na teoria e na prática: como estudar o ativismo através da fronteira entre estado e sociedade? Sociologias, 13(28): 52-84.

American Psychiatry Association (2013). DSM-V: Diagnostic and Statistical Manual of Mental Disorders. 5a edição. Washington: American Psychiatric Association.

Arendt, H. (2014). A Condição Humana. Rio de Janeiro: Forense Universitária.

Bento, B. (2006). A (re)invenção do corpo: sexualidade e gênero na experiência transexual. Rio de Janeiro: Garamond / CLAM.

Butler, J. (2011). Violencia de estado, guerra, resistencia. Por una nueva política de la izquierda. Madrid: Katz Ediciones. 
Butler, J. (2015). Quadros de Guerra. Rio de Janeiro: Civilização Brasileira.

Butler, J. (2018). Corpos em Aliança e a Política das Ruas. Rio de Janeiro: Civilização Brasileira.

Foucault, M. (1999). A verdade e as formas jurídicas. Rio de Janeiro: Nau.

Foucault, M. (1997). Microfísica do poder. Rio de Janeiro: Jorge Zahar.

Jesus, J. (2015). Homofobia: identificar e prevenir. 1 ed. Rio de Janeiro: Metanoia.

Lima, S.; Machado, P. \& Pereira, P. (2017). (Des)encontros no hospital: itinerário terapêutico de uma experiência intersexo. Cad. Pagu, (49), e174916. Campinas.

Mbembe, A. (2018). Necropolítica. São Paulo: n-1 edições.

Machado, J. A. (2007). Ativismo em rede e conexões identitárias: novas perspectivas para os movimentos sociais. Sociologias, (18): 248-285.

Oliveira, A. (2014). Os homens transexuais brasileiro, e o discurso pela (des) patologização da transexualidade. In J. G. Jesus (org), Transfeminismo: teorias \& práticas. Rio de Janeiro: Metanoia.

Organização Mundial da Saúde (1997). CID-10: Classificação Estatística Internacional de Doenças e Problemas Relacionados à Saúde. 10a rev. São Paulo: Universidade de São Paulo.

Prado, M. (2018). Ambulare. Belo Horizonte (MG): PPGCOM UFMG.

Rodrigues, L. R. A. (2018) Do encontro previsível à cena revigorada - a entrevista no documentário contemporâneo (parte 2). Doc On-Line, (23): 77-104.

Salles, J. M. (2005). A dificuldade do documentário. In J. S. Martins, C. Eckert \& S. Caiuby Novaes, O imaginário e o poético nas Ciências Sociais (pp. 57-71). Bauru: EDUSC.

\section{Filmografia}

Meu Corpo é Político (2017), de Alice Riff. 